\title{
Structure of spliceosomal ribonucleoproteins
}

\section{Daniel Aaron Pomeranz Krummel ${ }^{1}$, Kiyoshi Nagai ${ }^{2}$ and Chris Oubridge ${ }^{2 *}$}

\author{
Addresses: ${ }^{1}$ Department of Biochemistry, MS009 Brandeis University, PO Box 549110, Waltham, MA 02454-9110, USA; ${ }^{2}$ Medical Research Council \\ Laboratory of Molecular Biology, Hills Road, Cambridge, CB2 0QH, UK \\ * Corresponding author: Chris Oubridge (cjo@mrc-lmb.cam.ac.uk) \\ Fl000 Biology Reports 2010, 2:39 (doi:10.34I0/B2-39)
}

The electronic version of this article is the complete one and can be found at: http://f1000.com/reports/biology/content/2/39

\begin{abstract}
Splicing of the precursors of eukaryotic mRNA and some non-coding RNAs is catalyzed by the 'spliceosome', which comprises five RNA-protein complexes (small nuclear ribonucleoproteins, or snRNPs) that assemble in an ordered manner onto precursor-mRNAs. Much progress has been made in determining the gross morphology of spliceosomal assembly intermediates. Recently, the first crystal structure of a spliceosomal snRNP has provided significant insight into assembly and architecture of spliceosomal snRNPs in general and the structure-function relationship of human UI snRNP in particular.
\end{abstract}

\section{Introduction and context}

Spliceosomes catalyze excision of introns and ligation of exons from precursor-mRNAs (pre-mRNAs) in a twostep trans-esterification reaction (Figure 1a). They are dynamic and comprise approximately 170 components during a round of splicing [1]. Integral to the spliceosome are the U1, U2, U4, U5, and U6 small nuclear ribonucleoproteins (snRNPs). Together with non-snRNP factors, snRNPs assemble in an ordered manner onto pre-mRNAs, recognizing (a) the junction between $5^{\prime}$ exon and intron (5' splice-site), (b) a conserved sequence within the intron (branch-site), and (c) the junction between the intron and $3^{\prime}$ exon ( $3^{\prime}$ splice-site). Assembly intermediates are designated $\mathrm{E}, \mathrm{A}, \mathrm{B}, \mathrm{B}^{*}$, and $\mathrm{C}$ complexes. Initially, U1 snRNP recognizes the $5^{\prime}$ splicesite and non-snRNP proteins bind the branch-site and 3 ' splice-site (E complex), and then U2 snRNP recognizes the branch-site (A complex). The U4/U6-U5 tri-snRNP joins to form B complex. Following structural/compositional rearrangements, U1 and U4 snRNPs are destabilized, with U1 displaced by U6, and an activated B complex ( ${ }^{*}$, containing U2, U5, and U6 snRNPs) catalyzes the first reaction. After significant further remodeling, $\mathrm{C}$ complex catalyzes the second reaction to yield spliced mRNA.

\section{Major recent advances}

I. Structural determination of snRNPs and their subcomplexes by electron microscopy

Spliceosomal snRNPs and their subcomplexes have been visualized by cryo-negative electron microscopy (CNEM) or single-particle cryo-electron microscopy (cryo-EM) (or both). Human U1 snRNP assumes a doughnut-shaped central structure from which emanate two protuberances, features observed in early negative-stained images and by cryo-EM $[2,3]$.

The structure of SF3b ( $450 \mathrm{kDa})$, a major component of U2 snRNP, was determined by CNEM at a resolution of approximately $10 \AA$ [4]. It resembles a 'bivalve shell' with a stalk-like protuberance (Figure $1 \mathrm{~b}$ ). Three of seven proteins of SF3b have well-characterized protein folds: SF3b155 has 22 HEAT repeats; p14 (SF3b14a) and SF3b49 have one and two RNA recognition motifs (RRMs), respectively. The authors of the paper attribute three 'distinctly shaped blobs' to the RRMs and a ladderlike arrangement of density to SF3b155 HEAT repeats. The position of p14 is significant because it cross-links to the branch-point adenosine when $\mathrm{U} 2$ snRNP is incorporated into the spliceosome [5]. U11 and U12 snRNPs are equivalent to U1 and U2 snRNPs, but for minor intron 
Figure I. Spliceosomal assembly cycle and structures of spliceosomal complexes in the cycle, as determined by electron microscopy

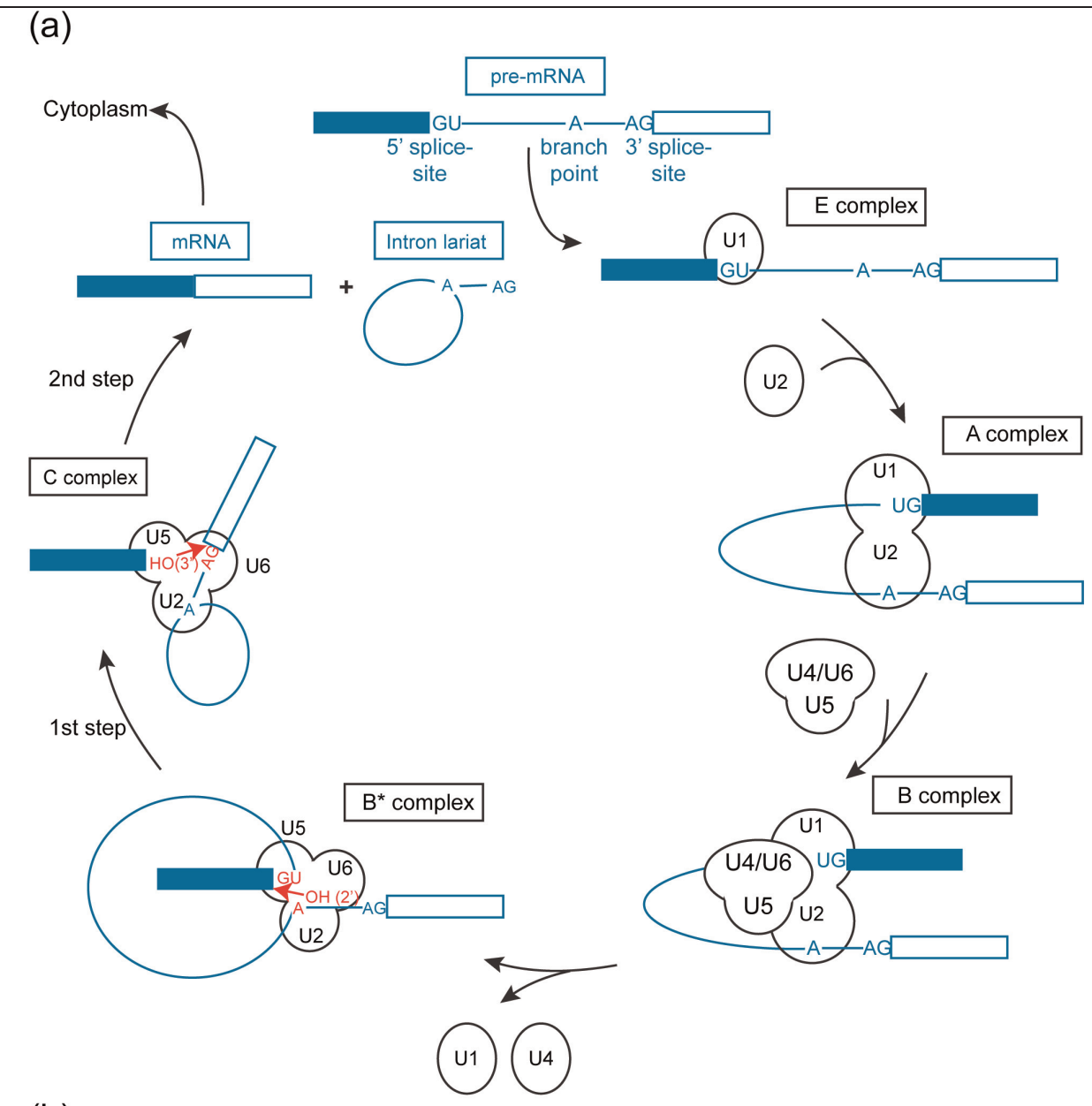

(b)

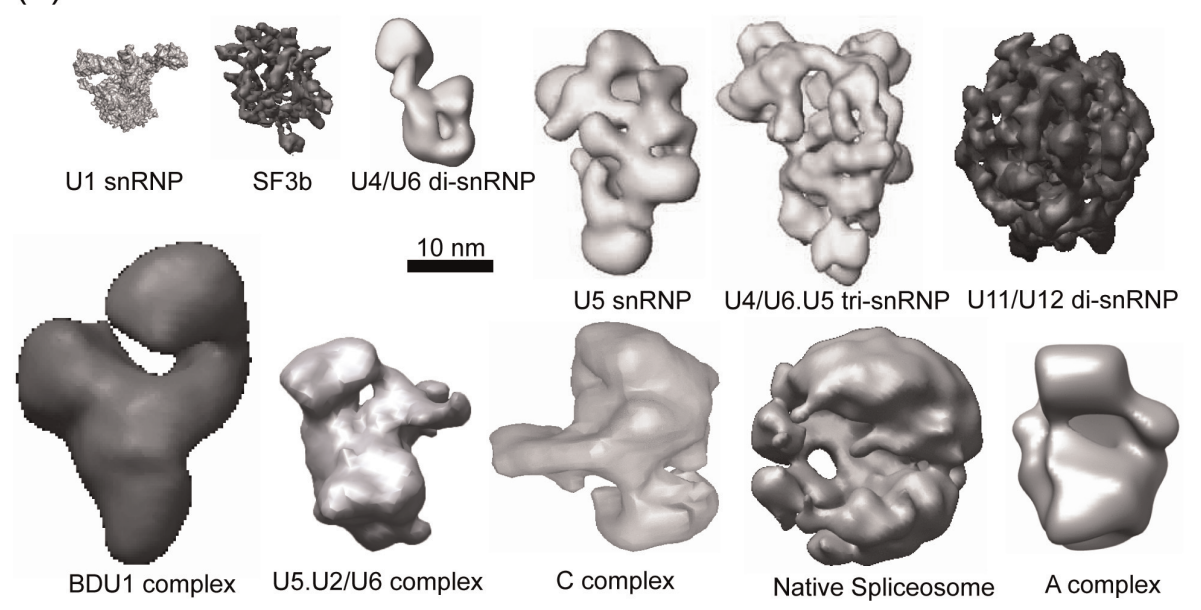

(a) $\mathrm{U}$ small nuclear ribonucleoproteins (snRNPs) assemble onto a precursor-mRNA (pre-mRNA) transcript and catalyze two trans-esterification reactions, which result in the splicing of two exons and the release of an intron in the form of a lariat-like structure. (b) Electron microscopy structures of spliceosomal assembly intermediates and U snRNPs: SF3b [4], U4/U6 di-snRNP, U5 snRNP and U4/U6.U5 tri-snRNP [8], UI I/UI2 di-snRNP [6], BAUI complex [I2], fission yeast U5.U2/U6 complex [19], C complex [17], native spliceosome [22], and the A complex [7]. Electron microscopy envelopes were obtained from the Electron Microscopy Data Bank [29]. A surface representation of the human UI snRNP crystal structure with modeled SL2 and UI-A RRMI (RNA recognition motif I) [23] is included for comparison. 
species, they function as a pre-formed U11/U12 di-snRNP (1.3 MDa). CNEM reveals an ellipsoidal structure with multiple protuberances [6] (Figure 1b). SF3b, also located within the di-snRNP, appears to adopt a more open conformation exposing p14 for interaction with the branch-point. A path for pre-mRNA across the di-snRNP is proposed on the basis of cross-links with identified protein components. The 1.8-MDa U4/U6-U5 tri-snRNP, determined at $21 \AA$ by both cryo-EM and CNEM [7], shows an elongate tetrahedron, approximately $30.5 \mathrm{~nm}$ in length (Figure 1b). U5 snRNP and U4/ U6 di-snRNP CNEM structures are also presented in this paper [7]. Comparison of particles showed that U5 snRNP, di-snRNP, and tri-snRNP all have rigid domains separated by flexible regions. By means of rigid-body fitting, U5 snRNP and U4/U6 di-snRNP structures were placed in the tri-snRNP. In this and a subsequent study [8], proteins were located in the tri-snRNP: U4/U6 di-snRNP proteins in an 'arm' domain, which can move relative to the rest of the particle; $\mathrm{U} 5$ proteins in a more static 'body' and 'head'; and tri-snRNP-specific proteins were found in a 'linker' region. Snu114, an elongation factor-G-like GTPase that regulates Brr2, is located near the hinge of the tri-snRNP, which allows the 'arm' to move. This raises the intriguing possibility that a conformational change of Snu114, driven by hydrolysis of GTP, powers the movement of the arm and brings the U4/U6 assembly into the proximity of Brr2, which can then unwind the base-paired region of the U4/U6 small nuclear ribonucleic acids (snRNAs).

\section{Structural determination of spliceosomal assembly intermediates by electron microscopy}

Splicing assembly intermediates have been prepared using pre-mRNA substrates that stall splicing at specific steps. Their structures have subsequently been investigated by Cryo-EM or CNEM (or both).

Human A complex contains all of the expected U1 and $\mathrm{U} 2$ snRNP proteins together with approximately 50 non-snRNP proteins. The CNEM structure reveals an asymmetrical particle consisting of a globular body, a head-like domain, and feet-like protrusions [9]. The A complex associates with the U4/U6-U5 tri-snRNP to form B complex. Around 100 proteins are associated with the B complex, which assumes a rhomboid shape, approximately $42 \mathrm{~nm}$ in its longest dimension [10]. The intron and both exons as well as U2 protein SF3b155 are located in its head domain [11]. U1 snRNP dissociates prior to formation of the activated $\mathrm{B}^{*}$ complex. A CNEM structure of B complex lacking U1 snRNP (BAU1) was determined at a resolution of approximately $40 \AA$ [12]. The structure features a mobile head domain linked to a roughly triangular body, similar in size and shape to the
U4/U6-U5 tri-snRNP. B complex activation requires major remodeling of RNA: base-pairing between U4/ U6 snRNAs is destabilized before formation of a U2/U6 snRNA structure. DExD/H-box helicases orchestrate these rearrangements $[13,14]$, leading to U4 snRNP dissociation and formation of activated $\mathrm{B}^{*}$ complex, which catalyzes the first trans-esterification reaction. Over 50 proteins are exchanged [15], and the structure of the megadalton U5 snRNP is dramatically altered during the transition from $\mathrm{B}$ to $\mathrm{B}^{*}$ complex [16]. A cryoEM structure of the human $\mathrm{C}$ complex at approximately 30 Å shows a particle consisting of three separate lobes in an open conformation [17]. A non-spliceosomal RNAbinding protein, with a shape that is readily identified by $\mathrm{EM}$, yielded insights into how complex $\mathrm{C}$ binds partially processed transcripts [18].

An approximately $29 \AA$ cryo-EM structure of a 37S spliceosomal complex from Schizosaccharomyces pombe resembles the human C complex (U5.U2/U6). This structure, with dimensions of approximately $30 \times 20 \times$ $18 \mathrm{~nm}$, is composed of distinct domains that contact each other at a central point [19]. Under certain low-salt conditions, complexes containing all five snRNPs together ('penta-snRNPs') have been isolated from yeast and human extracts $[20,21]$ but their functional significance is unclear. An approximately $20 \AA$ cryo-EM structure of a 'native' 200S spliceosome, purified from human cell nuclei, has an elongate structure made up of two globular bodies connected by a tunnel-like mesh. This 21-MDa particle is approximately $28 \mathrm{~nm}$ in its longest dimension [22]. The larger of the two bodies could accommodate a 'penta-snRNP'. The tunnel-like structure between the bodies is proposed to accommodate pre-mRNA.

\section{Crystal structure of a $U$ snRNP}

Each spliceosomal snRNP is composed of a single RNA molecule (U snRNA), a set of seven Sm or LSm proteins, and snRNP-specific proteins. Human U1 snRNP ( $245 \mathrm{kDa}, 11$ subunits) contains three U1-specific proteins: U1-70k, U1-A, and U1-C (Figure 2a). The crystal structure of a fully recombinant, 10-subunit human U1 snRNP at a resolution of $5.5 \AA$ [23] revealed a hierarchical network of interactions between U1 snRNP subunits. Seven Sm proteins form a ring around the single-stranded Sm site, which fans out through its center (Figure 2b). Strikingly, the N-terminus of U1-70k extends approximately $180 \AA$ from its RRM, which recognizes loop I of U1 snRNA, wrapping 'underneath' the entire Sm ring to finally contact U1-C, which is poised to recognize the $5^{\prime}$ splicesite. The circuitous path of U1-70k was unambiguously determined by a 'selenium-walk' through the electron density map [24]. The conserved, single-stranded $5^{\prime}$ end of U1 snRNA base-pairs with the $5^{\prime}$ splice-site, initiating 
Figure 2. Structure of human UI small nuclear ribonucleoprotein (snRNP) [23]

(a)

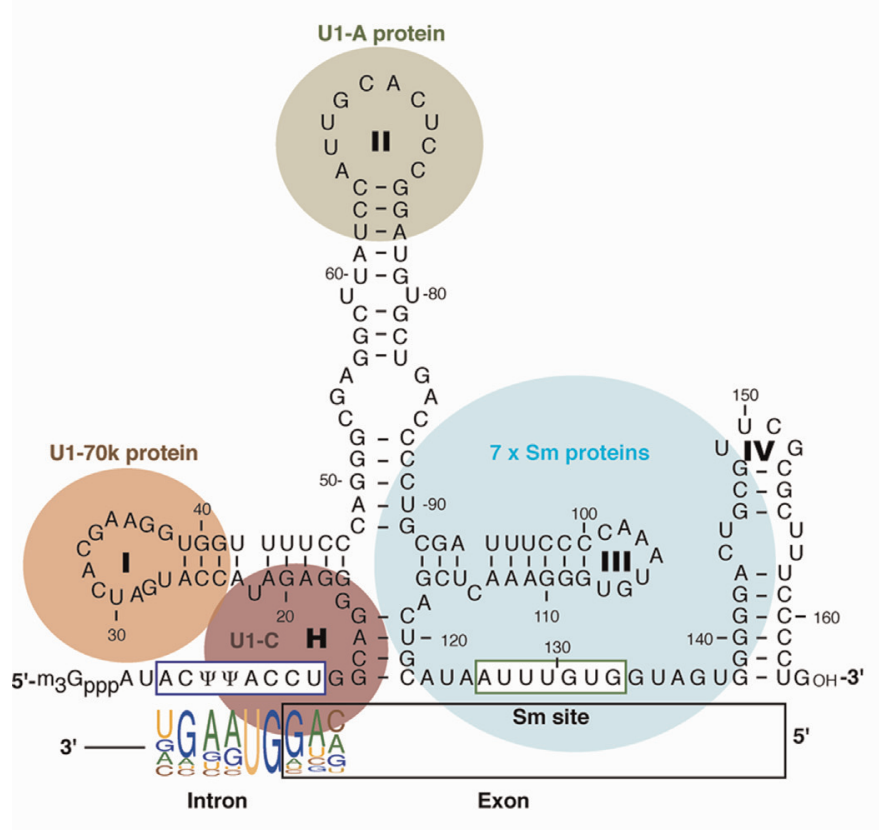

(b)

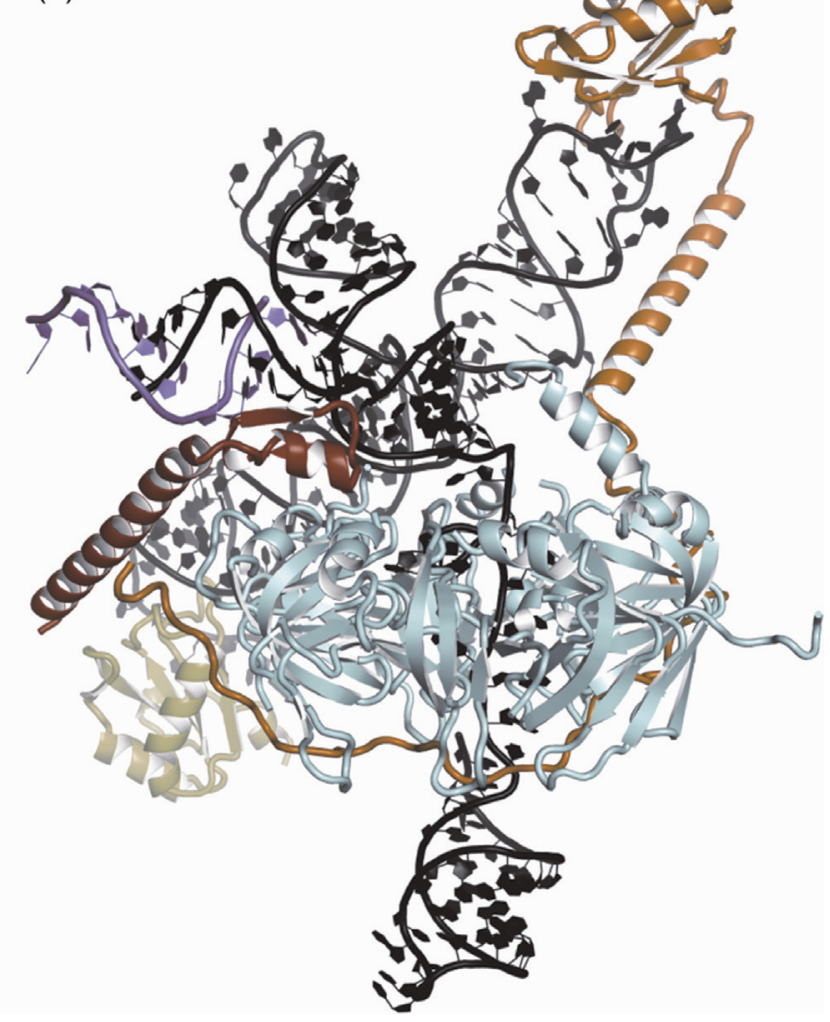

(a) Secondary structure of UI small nuclear ribonucleic acid (snRNA) (black) and general location of the seven Sm proteins (cyan), UI-70k (peachy brown), UI-A (green), and UI-C (maroon). A consensus $5^{\prime}$ splice-site is indicated, base-pairing to the single-stranded $5^{\prime}$ end of UI snRNA. (b) Crystal structure of UI snRNP with SL2 and UI-A RRMI (RNA recognition motif I) modeled. The structure is color-coded as in (a), with the $5^{\prime}$ splice-site mimic RNA colored blue.

pre-mRNA recognition. In U1 snRNP crystals, the $5^{\prime}$ end of one U1 snRNA interacts with the $5^{\prime}$ end from an adjacent particle such that they mutually mimic the $5^{\prime}$ splice-site. U1-C from each particle interacts with the resulting RNA duplex. The EM structure of U1 snRNP shows a ringshaped core domain with two large protuberances [3]. The ring-shaped core domain was interpreted as the Sm ring; it has a funnel-shaped hole passing through it. In the crystal structure, the four-helix junction lies directly over the center of the Sm ring and no such hole is observed; therefore, the interpretation of the EM envelope is not consistent with the crystal structure.

\section{Future directions}

Significant progress has been made toward determining the overall architecture of the spliceosome and its constituent snRNPs, particularly U1. In the future, improvements in EM structural resolution are expected, possibly facilitated by cross-linking [25], but ultimately the preparation of compositionally and structurally homogeneous samples is pivotal. Better purification strategies to identify stable core structures should yield better samples [26]. Improvements in labeling to localize pre-mRNA/proteins and dock higher-resolution structures of proteins or larger complexes will also be critical to provide a clearer picture of the spliceosome in its entirety. Further understanding of a 'native' complex structure, how post-translational modifications may alter structure [27], and the dynamics of assembly [28] will further enhance our understanding of this huge, dynamic machine: the spliceosome.

\section{Abbreviations}

CNEM, cryo-negative electron microscopy; cryo-EM, cryoelectron microscopy; EM, electron microscopy; RRM, RNA recognition motif; snRNA, small nuclear ribonucleic acid; snRNP, small nuclear ribonucleoprotein.

\section{Competing interests}

The authors declare that they have no competing interests. 


\section{Acknowledgments}

We thank Andy Newman for critical reading of the manuscript and Melanie Ohi for sending us the fission yeast U5.U2/U6 EM map. The U1 snRNP project was funded by the Medical Research Council of the UK and the Human Frontier Science Program (HFSP). DAPK was a recipient of an HFSP long-term fellowship.

\section{References}

I. Wahl MC, Will CL, Lührmann R: The spliceosome: design principles of a dynamic RNP machine. Cell 2009, I36:70I-I8.

2. Kastner B, Kornstadt U, Bach M, Luhrmann R: Structure of the small nuclear RNP particle UI: identification of the two structural protuberances with RNP-antigens A and 70K. J Cell Biol 1992, I I 6:839-49.

3. Stark H, Dube P, Luhrmann R, Kastner B: Arrangement of RNA and proteins in the spliceosomal UI small nuclear ribonucleoprotein particle. Nature 200I, 409:539-42.

4. Golas MM, Sander B, Will CL, Lührmann R, Stark H: Molecular architecture of the multiprotein splicing factor SF3b. Science 2003, 300:980-5.

FI000 Factor 4.8 Must Read

Evaluated by Peter Qin 16 May 2003, Eva Nogales 16 Jun 2003

5. MacMillan AM, Query CC, Allerson CR, Chen S, Verdine GL, Sharp PA: Dynamic association of proteins with the premRNA branch region. Genes Dev 1994, 8:3008-20.

6. Golas MM, Sander B, Will CL, Lührmann R, Stark H: Major conformational change in the complex SF3b upon integration into the spliceosomal UI I/U I 2 di-snRNP as revealed by electron cryomicroscopy. Mol Cell 2005, I 7:869-83.

7. Sander B, Golas MM, Makarov EM, Brahms H, Kastner B, Lührmann R, Stark H: Organization of core spliceosomal components U5 snRNA Loop I and U4/U6 di-snRNP within U4/U6.U5 trisnRNP as revealed by electron cryomicroscopy. Mol Cell 2006, 24:267-78.

FI000 Factor 6.0 Must Read

Evaluated by Kiyoshi Nagai 02 Nov 2006

8. Häcker I, Sander B, Golas MM, Wolf E, Karagöz E, Kastner B, Stark H, Lührmann R: Localization of Prp8, Brr2, Snul 14 and U4/U6 proteins in the yeast tri-snRNP by electron microscopy. Nat Struct Mol Biol 2008, I 5:| 206-I2.

9. Behzadnia N, Golas MM, Hartmuth K, Sander B, Kastner B, Deckert ], Dube P, Will CL, Urlaub H, Stark H, Lührmann R: Composition and three-dimensional EM structure of double affinity-purified, human prespliceosomal A complexes. EMBO J 2007, 26: I737-48.

10. Deckert J, Hartmuth K, Boehringer D, Behzadnia N, Will CL, Kastner B, Stark H, Urlaub H, Lührmann R: Protein composition and electron microscopy structure of affinity-purified human spliceosomal B complexes isolated under physiological conditions. Mol Cell Biol 2006, 26:5528-43.

II. Wolf E, Kastner B, Deckert J, Merz C, Stark H, Lührmann R: Exon, intron and splice site locations in the spliceosomal B complex. EMBO J 2009, 28:2283-92.

12. Boehringer D, Makarov EM, Sander B, Makarova OV, Kastner B, Lührmann R, Stark H: Three-dimensional structure of a precatalytic human spliceosomal complex B. Nat Struct Mol Biol 2004, I I:463-8.

13. Konforti BB, Koziolkiewicz MJ, Konarska MM: Disruption of base pairing between the $5^{\prime}$ splice site and the $5^{\prime}$ end of UI snRNA is required for spliceosome assembly. Cell 1993, 75:863-73.

14. Konforti BB, Konarska MM: U4/U5/U6 snRNP recognizes the $\mathbf{5}^{\prime}$ splice site in the absence of U2 snRNP. Genes Dev 1994, 8: 1962-73.
15. Bessonov S, Anokhina M, Will CL, Urlaub H, Lührmann R: Isolation of an active step I spliceosome and composition of its RNP core. Nature 2008, 452:846-5I.

16. Makarov EM, Makarova OV, Urlaub H, Gentzel M, Will CL, Wilm M, Lührmann R: Small nuclear ribonucleoprotein remodeling during catalytic activation of the spliceosome. Science 2002, 298:2205-8.

FI000 Factor 3.0 Recommended

Evaluated by Gabriele Varani 21 Mar 2003

17. Jurica MS, Sousa D, Moore MJ, Grigorieff N: Three-dimensional structure of C complex spliceosomes by electron microscopy. Nat Struct Mol Biol 2004, I I:265-9.

FI000 Factor 3.0 Recommended

Evaluated by Samuel Butcher 18 Mar 2004

18. Alcid EA, Jurica MS: A protein-based EM label for RNA identifies the location of exons in spliceosomes. Nat Struct Mol Biol 2008, I5:2। 3-5.

19. Ohi MD, Ren L, Wall JS, Gould KL, Walz T: Structural characterization of the fission yeast U5.U2/U6 spliceosome complex. Proc Natl Acad Sci U S A 2007, 104:3 I 95-200.

20. Stevens SW, Ryan DE, Ge HY, Moore RE, Young MK, Lee TD, Abelson J: Composition and functional characterization of the yeast spliceosomal penta-snRNP. Mol Cell 2002, 9:31-44.

FI000 Factor 9.7 Exceptional

Evaluated by Jon Lorsch 06 Feb 2002, Jonathan R Warner 20 Feb 2002, Adrian Krainer 10 Apr 2002

21. Malca H, Shomron N, Ast G: The UI snRNP base pairs with the $\mathbf{5}^{\prime}$ splice site within a penta-snRNP complex. Mol Cell Biol 2003, 23:3442-55.

22. Azubel M, Wolf SG, Sperling J, Sperling R: Three-dimensional structure of the native spliceosome by cryo-electron microscopy. Mol Cell 2004, 1 5:833-9.

23. Pomeranz Krummel DA, Oubridge C, Leung AKW, Li J, Nagai K: Crystal structure of human spliceosomal UI snRNP at $5.5 \AA$ resolution. Nature 2009, 458:475-8I.

FI000 Factor 8.2 Exceptional

Evaluated by Robert Batey 08 Apr 2009, Anne-Catherine DockBregeon 20 Apr 2009, Nathan Nelson 18 May 2009

24. Oubridge C, Pomeranz Krummel DA, Leung AKW, Li J, Nagai K: Interpreting a low resolution map of human U I snRNP using anomalous scatterers. Structure 2009, I7:930-8.

FI000 Factor 3.0 Recommended

Evaluated by Robert Batey 30 Jul 2009

25. Kastner B, Fischer N, Golas MM, Sander B, Dube P, Boehringer D, Hartmuth K, Deckert J, Hauer F, Wolf E, Uchtenhagen H, Urlaub H, Herzog F, Peters JM, Poerschke D, Lührmann R, Stark H: GraFix: sample preparation for single-particle electron cryomicroscopy. Nat Methods 2008, 5:53-5.

26. Fabrizio $P$, Dannenberg J, Dube $P$, Kastner B, Stark $H$, Urlaub $H$, Lührmann R: The evolutionarily conserved core design of the catalytic activation step of the yeast spliceosome. Mol Cell 2009, 36:593-608.

27. Hernández H, Makarova OV, Makarov E, Morgner N, Muto $Y$, Pomeranz Krummel DA, Robinson CV: Isoforms of Ul-70k control subunit dynamics in the human spliceosomal $\mathrm{U}$ snRNP. PLoS One 2009, 4:e7202.

28. Crawford DJ, Hoskins AA, Friedman LJ, Gelles J, Moore MJ: Visualizing the splicing of single pre-mRNA molecules in whole cell extract. RNA 2008, I4:I70-9.

29. Electron Microscopy Data Bank (EMDB) at EBI. [http://www. ebi.ac.uk/pdbe/emdb/] 